\title{
FunçõES DO REMANESCENTE ESPLÊNICO APÓS ESPLENECTOMIA SUBTOTAL PARA O TRATAMENTO DE LESÕES COMPLEXAS DO BAÇO HUMANO
}

*Viviam Resende, Andr Petrolanu

Trabalho realizado na Universidade Federal de Minas Gerais (UFMG) e Hospital João XXIII (FHEMIG-Fundação Hospitalar do Estado de Minas Gerais)

RESUMO - OBJetivo. Verificar a possibilidade de realizar esplenectomia subtotal na presença de lesões graves do baço por trauma ou que acometam o seu pedículo vascular principal, avaliar as repercussões clínicas, hematológicas e imunológicas que essa operação pode trazer nos pós-operatórios, viabilidade e a função de filtração do pólo superior do baço remanescente.

Métodos. Foram estudados 34 pacientes, 25 submetidos à esplenectomia subtotal (Grupo I), nove à esplenectomia total sem preservação de tecido esplênico (Grupo II), 22 pessoas com baços íntegros (Grupo III). No pós-operatório tardio realizaram-se exames hematológicos (hematimetria, hemoglobina, hematócrito, plaquetas, leucócitos globais e segmentados, linfócitos e corpúsculos de Howell Jolly). Dosaram-se as imunoglobulinas (IgA, IgM e IgG) e linfócitos T totais (LTT), linfócitos T ativos
(LTA) e linfócitos B. Realizou-se cintilografia esplênica com enxofre coloidal marcado com ${ }^{99 \mathrm{~m}} \mathrm{Tc}$.

Resultados. Em nenhum dos grupos houve leucocitose ou trombocitose. Os corpúsculos de Howell-Jolly foram observados no Grupo II e neste grupo a IgM esteve reduzida. A cintilografia demonstrou tecido esplênico captante no Grupo I.

Conclusão. A esplenectomia subtotal pode ser uma alternativa cirúrgica para as lesões graves distais do baço ou quando o seu pedículo principal estiver acometido e não leva a repercussões clínicas e laboratoriais nos pacientes submetidos a esse procedimento.

Unitermos: Baço/lesões. Esplenenectomia. Baço/fisiologia. Baço/ imunologia.

\section{INTRODUÇÃO}

O baço, como órgão do sistema mononuclear fagocitário, tem importante papel na defesa orgânica devido a seus mecanismos de filtração e fagocitose, além da produção de fatores do complemento e imunoglobulinas, em especial a lgM!' Asua importância pode ser comprovada pela gravidade da sepse que atinge mais de $2 \%$ de indivíduos esplenectomizados, com maior destaque em crianças, que possuem o sistema imunitário ainda imaturo, e em pessoas imunodeprimidas.

*Correspondência:
Vivian Resende
Rua Sergipe, $n^{\circ}$ 67, apto 2401
Bairro Funcionários - CEP: 30130-170
Belo Horizonte - MG - Tel.: (31) 3222-7763

Nos serviços de emergência, observa-se que após o fígado, o baço é um dos órgãos intra-abdominais mais freqüentemente lesados, principalmente em crianças vítimas de traumatismos abdominais contusos. Muitas vezes, a gravidade do quadro levaà realização de esplenectomias totais. Entre as muitas complicações decorrentes desse procedimento, os fenômenos sépticos, como a pneumococcemia fulminante, são os mais indesejáveis ${ }^{1,2,3,4}$. Diante da gravidade da "síndrome pós-esplenectomia", a esplenectomiatotal tem sido cada vez menosadotada para tratar lesões menos graves do baç5,6,7.

A preservação do pólo superior do baço, após a ligadura de seu pedículo vascular, proposta em 1982, tem sido estudada clínica e experimentalmente em diversos trabathos e vem sendo realizada com sucesso desde 1984. Bons resultados foram obtidos com esse procedimento em hipertensão porta, doença de Gaucher, mielofibrose com metaplasia mielóide, leucemia linfocítica crônica e afecções corpo-caudais do pâncreas e, mais recentemente, foi por nós descrito no trauma um estudo preliminar com a esplenectomia subtotal ${ }^{8-20}$.

Devido ao fato de o baço ser um dos órgãos intra-abdominais mais lesados nos traumatismos abdominais contusos e diante de sua importância na defesa do organismo, foi proposto realizar o presente estudo cujos objetivosfundamentais foram verificar a possibilidade de realizar esplenectomia subtotal na presença de lesões graves do baço por trauma ou que acometam o seu pedículo vascular principal, avaliar as repercussões clínicas que essa operação pode 
trazer nos pós-operatórios imediato e tardio, verificar a viabilidade e a função de filtração do pólo superior do baço remanescente e analisar as repercussões hematológicas e imunológicas em pacientes submetidos a esse procedimento.

\section{Métodos}

No período de janeiro de 1994 a janeiro de 1998 foram estudados 34 pacientes com lesões esplênicas graves que comprometiam os vasos hilares. Para se ter referência laboratorial dos resultados, foram utilizados outros 22 pacientes sadios e com baços íntegros. Os pacientes foram divididos nos seguintes grupos: Grupo I $(n=25)$ esplenectomia subtotal, Grupo II $(n=9)$ controle - esplenectomia total, Grupo III (n = 22) - controle-normal.

Os índices de trauma calculados foram o RTS (Revised Trauma Score), ISS (Injury Severity Score) e o TRISS (Trauma Index Severity Scale). Investigou-se o mecanismo do trauma (Tabela I). A Tabela 2 mostra a distribuição dos pacientes quanto à idade, sexo, médias dos índices de trauma e métodos propedêuticos.

Após a mobilização do baço para o campo operatório, ligaram-se os vasos esplênicos com fio de seda 2-0. Tomou-se o cuidado para preservar o ligamento esplenogástrico. O corte esplênico foi na transição entre o pólo superior, que se manteve róseo, e o restante do órgão. O baço foi seccionado em cunha, preservando-se a maior quantidade possível de cápsula em dois retalhos: um anterior e outro posterior. O sangramento dos vasos mais calibrosos do parênquima esplênico foi controlado com sutura, utilizando-se fio de categute simples 3-0. O sangramento de menor intensidade cessou com uma sutura em barra grega, transfixante de todo o parênquima esplênico, utilizando-se fio de categute cromado 2-0 montado em agulha cilíndrica de

\begin{tabular}{|c|c|c|c|}
\hline Mecanismo do trauma & Grupol & Grupo II & Total \\
\hline Acidente automobilístico & 5 & | & 6 \\
\hline Atropelamento & $\|$ & 4 & 15 \\
\hline Queda de bicicleta & । & i & 2 \\
\hline Queda demotocicleta & 3 & - & 3 \\
\hline Quedade attura & । & 3 & 4 \\
\hline Armadefogo & 3 & - & 3 \\
\hline Armabranca & & | & -1 \\
\hline Total & 25 & 9 & 34 \\
\hline
\end{tabular}

Tabela 2 - Número de pacientes, idades, índices de trauma e diagnóstico em pacientes submetidos a esplenectomia subtotal (Grupo I) e esplenectomia total sem preservação de tecido esplênico (Grupo II)

\begin{tabular}{|c|c|c|}
\hline Parâmetro & Grupo I & Grupo II \\
\hline Idade & & \\
\hline Faixa (M \pm DPM) & $21,56 \pm 11,80$ & $30,55 \pm 14,29$ \\
\hline \multicolumn{3}{|l|}{ Sexo } \\
\hline Masculino & 21 & 6 \\
\hline Feminino & 4 & 3 \\
\hline \multicolumn{3}{|l|}{ Índices de trauma } \\
\hline $\begin{array}{l}\text { MédiaRTS } \\
\text { MédialSS } \\
\text { Média TRISS }\end{array}$ & $\begin{array}{r}7,56 \pm 0,78 \\
21,28 \pm 6,12 \\
97,80 \pm 3,15\end{array}$ & $\begin{array}{c}7,29 \pm 0,95 \\
28,00 \pm 2,00 \\
93,40 \pm 11,19\end{array}$ \\
\hline \multicolumn{3}{|l|}{ Método diagnóstico } \\
\hline Clínico & 8 & - \\
\hline US & 16 & 7 \\
\hline TC & 6 & I \\
\hline PD & I & 2 \\
\hline
\end{tabular}

M:média

DPM: desvio padrãoda média

US:ultra-sonografia

TC: tomografia computadorizada

LPD: lavado peritoneal diagnóstico

$5 \mathrm{~cm}$. Uma segunda sutura contínua com fio de categute cromado 2-0 ou poligalactina $910\left(\right.$ Vicry $\left.^{R}\right)$ 3-0 aproximou os dois retaIhos da cápsula esplênica. O pólo superior remanescente do baço foi recolocado na loja esplênica.

Procedeu-se ao acompanhamento clíni- co e identificaram-se as complicações pósoperatórias imediatas. Determinou-se a permanência hospitalar. Após serem liberados do hospital, os pacientes foram controlados ambulatorialmente duante dois anos.

Decorridos no mínimo três meses da cirurgia, os pacientes foram contactados 
ResendeA et al.

para fazerem o controle tardio da operação. Investigou-se a história de infecções ou doenças concomitantes que pudessem interferir na interpretação dos exames laboratoriais hematológicos e imunológicos. Coletou-se $2 \mathrm{ml}$ de sangue com anticoagulante (EDTA) de cada doente e realizou-se hemograma que quantificou as hemácias, hemoglobina, hematócrito, plaquetas, leucócitos globais, leucócitos segmentados e linfócitos. Os esfregaços de sangue obtidos dessas amostras de sangue foram corados pelo método de May-GrünwaldGiensa para pesquisa de corpúsculos de Howell-Jolly. Coletou-se $10 \mathrm{ml}$ de sangue em frasco contendo heparina e dosaram-se as imunoglobulinas e linfócitos. O método utilizado para a dosagem de imunoglobulinas foi imunodifusão em Agar ${ }^{19}$.

Os linfócitos foram obtidos por centrifugação de amostras de sangue heparinizado com gradiente Ficoll/Hypaque. Linfócitos T ativos, linfócitos $B$ e linfócitos $T$ total foram quantificados pela incubaçãa de volumes iguais de linfócitos e hemácias de carneiro $(0,5 \%)$. A porcentagem de rosetas foi determinada utilizando-se microscopia de luz.

Realizou-se cintilografia esplênica com enxofre coloidal marcado com tecnécio-99 $\left({ }^{99 m} \mathrm{Mc}\right)$. Os exames foram avaliados quanto à captação do radiofármaco pelo tecido esplênico nas incidências - anterior, posterior, oblíqua anterior esquerda, oblíqua posterior esquerda e lateral esquerda. Nos pacientes comesplenectomiatotal sem preservação de tecido esplênico procurou-se focos de esplenose em toda a cavidade peritoneal.

As comparações quanto às variáveis do hemograma e do perfil imunológico entre os grupos foram feitas utilizando-se o teste de Kruskal-Wallis. Todos os resultados foram considerados significativos a um nível de significância de 5\% ( $p<0,05)$, tendo portanto, $95 \%$ de confiança de que os resultados foram corretos.

\begin{tabular}{|c|c|c|c|c|c|c|}
\hline \multicolumn{7}{|c|}{$\begin{array}{c}\text { Tabela } 3 \text { - Análise descritiva e comparativa das variáveis do hemograma } \\
\text { no pós-operatório tardio nos grupos estudados }\end{array}$} \\
\hline \multirow[b]{2}{*}{$\begin{array}{l}\text { Variável } \\
H \mathrm{tm}\left(\mathrm{mm}^{3}\right)\end{array}$} & \multicolumn{6}{|c|}{ Medidas Descritivas } \\
\hline & $\begin{array}{c}\text { Grupo } \\
\|\end{array}$ & $\begin{array}{l}\text { Mínimo } \\
446 \\
421\end{array}$ & $\begin{array}{c}\text { Máximo } \\
575 \\
593\end{array}$ & $\begin{array}{c}\text { Média } \\
486 \\
482\end{array}$ & $\begin{array}{c}\text { Desvio-padrão } \\
36 \\
59\end{array}$ & $\begin{array}{l}\mathbf{p} \\
\mid=\|\end{array}$ \\
\hline $\mathrm{Hb}(g / d)$ & । & $\begin{array}{l}12,0 \\
12,2\end{array}$ & $\begin{array}{l}16,2 \\
16,6\end{array}$ & $\begin{array}{l}13,5 \\
14,0\end{array}$ & $\begin{array}{l}1,2 \\
1,8\end{array}$ & $1=\|$ \\
\hline $\mathrm{Htc}(\%)$ & । & 37 & 50 & 42 & 4 & \\
\hline & $\|$ & 38 & 51 & 43 & 5 & I=III \\
\hline Plaquetas $\left(\mathrm{mm}^{3}\right)$ & । & 198 & 458 & 280 & 69 & \\
\hline & $\|$ & 203 & 459 & 312 & 99 & $1=\|$ \\
\hline$L G\left(\mathrm{~mm}^{3}\right)$ & । & 4.500 & 10.400 & 7.400 & 2.034 & \\
\hline & $\|$ & 4.600 & 11.700 & 7.586 & 2.381 & I=\|l \\
\hline$L G\left(\mathrm{~mm}^{3}\right)$ & I & 28 & 70 & 51 & 10 & \\
\hline & $\|$ & 35 & 65 & 55 & 10 & $1=\|$ \\
\hline Li $(\%)$ & | & 22 & 66 & $4 \mid$ & 10 & \\
\hline & $\|$ & 27 & 56 & 40 & 10 & $1=\|$ \\
\hline
\end{tabular}

\section{Nota:}

Legenda de Grupo:

I. Esplenectomiasubtotal

II. Controle - Esplenectomiatotal

Htm: hematimetria, Hb: Hemoglobina, Htc: Hematócrito, LG: Leucócito Global, Se:Segmentado, Li:

Linfócito.

Ovalor de pnatabela refere-sea probabilidade de significância doteste de Kruskal-Wallis.

\section{Resultados}

O período de internação no Grupo 1 variou de 4 a 60 dias $(12,52 \pm 14,28)$. Apenas dois doentes desenvolveram infecção intra-abdominal pós-operatória, ambos apresentavam lesões associadas de outros órgãos intra-abdominais (pâncreas, fígado, cólon, rim, duodeno). Um deles desenvolveu abscesso subfrênico à equerda que foi tratado com sucesso por meio de drenagem percutânea dirigida por tomografia computadorizada e uso de antimicrobianos. Essa tomografia, feita no pós-operatório, mostrou o remanescente esplênico sem abscesso em seu parênquima. Outro paciente apresentou infecção no trajeto do dreno abdominal que permaneceu portempo pro- longado por causa de uma fístula pancreática. Um outro doente, que foi politransfundido, desenvolveu hipocoagulabilidade sangüínea e, posteriormente, infecção pulmonar, permanecendo por longo tempo na unidade de terapia intensiva.

Operíodo de permanência hospitalar no Grupo II variou de 5 a 35 dias (10,78 \pm 9,56). Um paciente desenvolveu infecção de ferida no membro inferior e outro teve embolia pulmonar gordurosa. Esse último teve fratura exposta de úmero. Alonga permanência hospitalar de alguns doentes deveu-se ao tratamento de lesões associadas e suas complicações.

$\mathrm{Na}$ avaliação pós-operatória tardia em nenhum dos grupos foi relatado episódio de 
Figura I. Imagem cintilográfica (enxofre coloidal - $99 \mathrm{mTc}$ ) do pólo superior esplênico, no décimo mês pós-operatório. Observar a captação esplênica (seta) e a hepática (*).

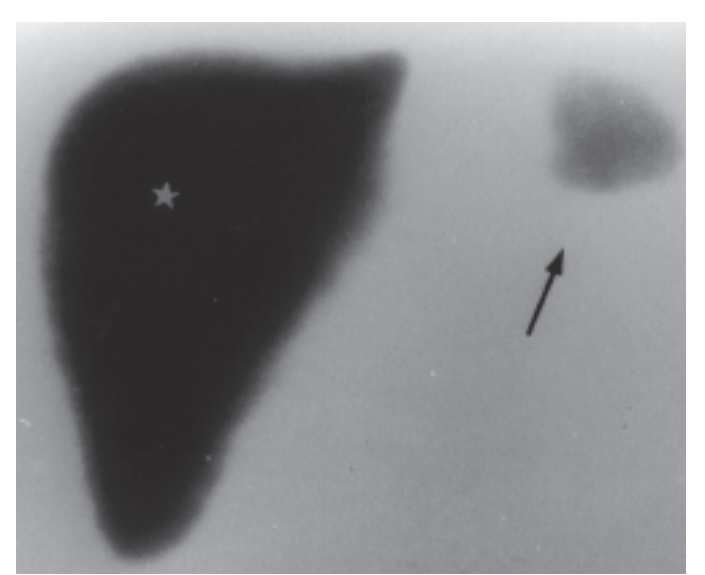

\begin{tabular}{|c|c|c|c|c|c|c|}
\hline \multicolumn{7}{|c|}{$\begin{array}{c}\text { Tabela } 4 \text { - Análise descritiva e comparativa das variáveis das características } \\
\text { imunológicas nos grupos estudados }\end{array}$} \\
\hline \multirow[b]{2}{*}{ Variável } & \multicolumn{6}{|c|}{ Medidas Descritivas } \\
\hline & Grupo & Mínimo & $\begin{array}{l}\text { Máximo } \\
57\end{array}$ & $\begin{array}{l}\text { Média } \\
31\end{array}$ & $\begin{array}{l}\text { Desvio-padrão } \\
13\end{array}$ & $p$ \\
\hline \multirow[t]{3}{*}{ LTA(\%) } & $\|$ & 22 & 53 & 41 & 12 & \multirow[t]{2}{*}{$l=\|=\|$} \\
\hline & $\|$ & 17 & 36 & 30 & 5 & \\
\hline & | & 50 & 74 & 60 & 7 & \multirow{3}{*}{$\mid=\|=\| \|$} \\
\hline \multirow[t]{3}{*}{ LTT(\%) } & $\|$ & 54 & 70 & 60 & 5 & \\
\hline & $\|$ & 52 & 74 & 63 & 5 & \\
\hline & I & 10 & 18 & 15 & 2 & \\
\hline \multirow[t]{3}{*}{$\mathrm{LB}(\%)$} & $\|$ & 12 & 17 & 15 & 2 & \multirow[t]{2}{*}{$\mid=\|>\| \|$} \\
\hline & $\|$ & 10 & 18 & 14 & 2 & \\
\hline & | & 30 & 220 & 128 & 50 & \multirow{3}{*}{$|=\|\mid>\|$} \\
\hline \multirow[t]{3}{*}{$\lg M(m g)$} & $\|$ & 30 & 150 & 71 & 41 & \\
\hline & $\|$ & 65 & 140 & 114 & 20 & \\
\hline & | & 115 & 800 & 307 & 165 & \multirow{3}{*}{$|=\|=|\||$} \\
\hline \multirow[t]{3}{*}{ |gA(mg) } & $\|$ & 40 & 430 & 245 & 124 & \\
\hline & $\|$ & 120 & 440 & 253 & 94 & \\
\hline & | & 820 & 1.670 & 1.234 & 257 & \multirow{3}{*}{$\mid=\|=\| \|$} \\
\hline \multirow[t]{2}{*}{$\lg G(m g)$} & $\|$ & 910 & 1.950 & 1.470 & 344 & \\
\hline & Oll & 900 & 1.530 & 1.176 & 194 & \\
\hline \multicolumn{7}{|c|}{$\begin{array}{l}\text { Nota: } \\
\text { Legendade Grupo: } \\
\text { I. Esplenectomiasubtotal } \\
\text { II. Controle-Esplenectomiatotal } \\
\text { III.Controle-normal } \\
\text { LTA: Linfócitos TAtivos, LTT: Linfócitos TTotais, LB: Linfócitos B, Ig: Imunoglobulinas M, AeG. } \\
\text { Ovalor de pnatabelarefere-sea probabilidade de significância do teste de Kruskal-Wallis }\end{array}$} \\
\hline
\end{tabular}

infecção grave. Uma criança do grupo com esplenectomia subtotal apresentou sinusite crônica refratária ao tratamento com antimicrobianos. Essa afecção já existia antes do procedimento cirúrgico.

Nos pacientes submetidos à esplenectomia subtotal não se observaram corpúsculos de Howell-jolly nos esfregaços de sangue periférico, enquanto que nos pacientes com esplenectomia total a média foi de 4 corpúsculos por 5 campos de hemácias examinadas.

Dos 17 pacientes submetidos à esplenectomia subtotal, em 15 os exames cintilográficos mostraram captação do enxofre coloidal marcado com ${ }^{99 m T c}$ pelos macrófagos do remanescente esplênico (Figura I) e em dois não se evidenciou tecido esplênico. A Tabela 3 mostra que não existe diferença significativa entre os dois tipos de esplenectomia em relação às variáveis que avaliam o hemograma. A Tabela 4 mostra que existem diferenças significativas entre os três grupos em relação à lgM.

\section{Discussão}

A esplenectomia subtotal contribuiu para que fosse mudado na literatura o conceito consagrado de que a esplenectomia total é obrigatória nas lesões do pedículo esplênico, uma vezque, estando o pólo superior íntegro, tal conduta poderia ser dispensada 21,22 .

A imunoprofilaxia para pneumococo e hemófilo não era feita rotineiramente nos pacientes esplenectomizados em nossa instituição. Mais recentemente é que se passou a adotar essa conduta. Entretanto, os pacientes dos grupos com esplenectomia subtotal foram orientados a nos procurar em qualquer situação que sugerisse quadro infeccioso.

A decisão quanto ao procedimento sobre o baço dependeu da gravidade da lesão esplênica. Nos casos em que a lesão foi extensa, acometendo vasos segmentares 
ResendeA et al.

maiores ou do hilo, mas que o pólo superior se manteve íntegro, a esplenectomia subtotal foi realizada. Asecção do baço e a sutura do remanescente esplênico foi facilmente exeqüivel e não prolongou muito o tempo cirúrgico. O tempo médio para se realizar a secção esplênica ea sutura do remanescente foi de 20 minutos.

As lesões associadas intra-abdominais não impediram a realização da esplenectomia subtotal. Na presente casuística houve apenas um caso de abscesso subfrênico à esquerda em um doente com lesões associadas de rim, veia cava inferior e cólon. Não acreditamos que a preservação esplênica tenha sido a causa dessa complicação pósoperatória, já que apenas a drenagem da coleção, mantendo-se o remanescente esplênico, curou o doente .

A maioria das complicações pós-operatórias não estiveram relacionadas ao trauma esplênico. Elas foram conseqüentes a lesões associadas intra ou extra-abdominais, como, por exemplo, fístula renal, fístula liquórica e osteomielite.

O tempo de permanência hospitalar foi variável, mas a maioria dos pacientes que não tiveram complicações pós-operatórias e recebeu alta hospitalar entre três a sete dias. Não houve complicação que possa ter sido atribuída à cirurgia sobre o baço.

No pós-operatório tardio não confirmamos a trombocitose persistente citada na literatura em pacientes esplenectomizados ${ }^{23}$. $\mathrm{Na}$ presente casuística a trombocitose ocorreuno pós-operatório imediato de alguns dos pacientes, alcançando picos nas duas a três semanas subseqüentes à esplenectomia subtotal regredindo posteriormente.

Ainda hoje a função do tecido esplênico não pode ser adequadamente avaliada, pois não existem parâmetros que mostrem diretamente a função esplênica. A função de filtração tem sido demonstrada pelo número de corpúsculos de Howell-Jolly no interior das hemácias ${ }^{20,21}$. A ausência dos corpúsculos de
Howell-Jolly nos esfregaços de sangue periférico dos pacientes submetidos à esplenectomia subtotal foi indicativa de que o tecido esplênico manteve sua função de filtração.

$\mathrm{Na}$ presente casuística o fato de ter-se constatado que os pacientes do Grupo I mantiveram níveis séricos normais da imunoglobulina M foi sugestivo de que o tecido esplênico remanescente representa um papel fundamental na síntese dessa imunoglobulina. O mesmo fato foi observado para a imunoglobulina $A$, sem entretanto, obtermos valores significativos. Existem controvérsias na literatura no que se refere aos níveis séricos de imunoglobulinas em pacientes esplenectomizados ${ }^{24-27}$. As diferenças observadas nas dosagens dos linfócitos B podem ter sido provocadas pela grande variação em seus valores, fato que pode ter causado tendência de diferenç̧a.

O método imunológico não foi o mais atual, entretanto, seus resultados são considerados válidos ${ }^{19}$. Técnicas mais modernas não foram acessíveis no hospital em que trabalhamos.

A cintilografia mostrou a função fagocitária do pólo superior. A captação do enxofre coloidal marcado com $^{99 m} \mathrm{Tc}$ indica que a função fagocitária se manteve mesmo semo pedículo vascular principal. O exame foi realizado após os três primeiros meses pósoperatórios para se ter certeza de que o tecido esplênico já havia regenerado. Nos 30 primeiros dias observa-se que existe uma redução na funçãofagocitária, provavelmente por isquemia e resposta inflamatória ocorrida neste período ${ }^{14}$.

Nos dois pacientes submetidos à esplenectomia subtotal, em que a cintilografia não mostrou tecido esplênico, pode ter ocorrido sobreposição do lobo esquerdo do fígado à imagem do baço. Quando a cintilografia

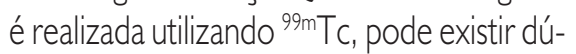
vida sobre a integridade esplênica devido a essa sobreposição de imagens, apesar de o exame ter sido realizado em várias posições.
Os resultados com eritrócitos marcados com ${ }^{99 m} T c$ é um método de maior acurácia em muitos casos, sem entretanto substituir o exame com o enxofre coloidal marcado com ${ }^{99 \mathrm{~m}} \mathrm{~T} \mathrm{c}$, rotineiramente utilizado, o qual é de maisfácil e rápida execução que o primeiro ${ }^{28}$.

\section{SUMMARY}

\section{FUNCTIONS OF THE SPLENIC REMNANT AFTER SUBTOTAL SPLENECTOMY FOR TREATMENT OF SEVERE SPLENIC INJURIES}

PURPOSE. To evaluate clinical and laboratory variables in patients submitted to subtotal splenectomy.

Methods. 34 patients with severe trauma ofthe spleen and its pedicle were studied: 25 patients were submitted to subtotal splenectomy, preserving only the upper pole of the spleen (Group I), 9 were submitted to total splenectomy (Group II), and other 22 people with intact spleen were the control (Group III). Immediate and late postoperative complications were investigated. Laboratory exams were performed in the late postoperative period (red blood cells, hemoglobin, white blood cells, platelets and Howell-Jolly bodies). We studied the B-and T-lymphocyte counts and the immunog/obulins $A, G$ and $M$ (IgA, IgG and IgM) levels. Splenic scintigraphy with technetium $99 m$ Tc sulfur colloid was carried out on all patients.

RESULTS. Group II presented HowellJolly bodies increased and low level of immunoglobulin M. The splenic scintigraphy demonstrated the viability and the filtering function of the splenic remnant in Group I.

ConCLusIons. Subtotal splenectomy is a surgicalalternative techniquefortreatment of severe distal injuries of the spleen or when its main vessels are damaged. [Rev Assoc Med Bras 2002; 48(I): 26-31]

KEY wORDS: Spleen/injuries. Splenectomy. Spleen/physiology. Spleen/immunology. 


\section{REFERÊNCIAS}

Babcock GF, Amoscato AA, Nishioda K. Effect of tuftisin on the migration, chemotaxis, and differentiation of macrophages and granulocytes. Ann NY Acad Sci 1983: 419:64-75.

2. King $H$, Shumacker-Jr HB. Susceptibility to infection after splenectomy performed in infancy. Ann Surg 1952; 136:239-242.

3. Malangoni MA, Dillon LD, Klamer TW, Condon RE. Factors influencing the risk of early and late serious infection in adults after splenectomy for trauma. Surgery 1984; 96:775-83

4. Pimpl W, Dapunt O, Kaindl H, Thalhamer J. Incidence of septic and thromboembolic related deaths after splenectomy in adults. $\mathrm{Br}$ J Surg 1989; 76:517-21.

5. Buntain WL. Splenic injuries. In: Buntain WL, editor. Management of pediatric trauma. Baltimore: W. B. Saunders; 1994. p.285$3 \mid 5$.

6. Morrell DG, Chang FC, Helmer SD. Changing trends in the management of splenic injury. Am J Surg 1995; 170: 686-90.

7. Brasel KJ, DeLisle CM, Olson CJ, Borgstrom DC. Splenic injury: trends in evaluation and management. J Trauma 1998; 44: 283-6.

8. Petroianu A. Esplenectomia subtotal and anastomose esplenorrenal proximal, para 0 tratamento da hipertensão portal. Rev Bras Cir 1983: 73: 101-4.

9. Petroianu A, Ferreira VL, Barbosa AJA Morphology and viability of the spleen after subtotal splenectomy. Braz J Biol Res 1989; 22: 49I-5.

10. Petroianu A. Splenic viability after segmental devascularization. Rev Paul Med 1992: I 10: $39-41$.
| I. Petroianu A. Avaliação imaginológica da subtotal splenectomy and anastomose esplenorrenal centralizada para o tratamento da hipertensão portal esquistossomática. Rev Méd Minas Gerais 1993; 3:106-8.

12. Petroianu A. Esplenectomia subtotal preservando o pólo superior suprido pelos vasos esplenogástricos. Rev Col Bras Cir 1993; $21: 21-6$

13. Petroianu A. Subtotal splenectomy and portal variceal disconnection in the treatment of portal hypertension. Can J Surg 1993; 36: 25I-4.

14. Petroianu A, Simal CJR, Barbosa AJA. Assessment of phagocytic function in remnants of subtotal splenectomy and in autologous spleen implantation. Med Sci Res 1993; 21:7|5-7.

15. Petroianu A, Petroianu S. Anatomy of splenogastric vessels in patients with schistosomal portal hypertension. Clin Anat 1994; 7: $80-3$.

16. Petroianu A. Treatment of cystadenoma of the pancreatic tail by distal pancreatectomy and subtotal splenectomy. Dig Surg 1995; 12: 259-61.

17. Petroianu A. Subtotal splenectomy in Gaucherłs disease. Eur J Surg 1996; 162: 51।-3.

18. Petroianu A, Silva, RG, Simal CIR, Carvalho DG, Silva RAP. Late postoperative follow-up of patients submitted to subtotal splenectomy. Am Surg 1997; 63: 735-40.

19. Petroianu A, Antunes LJ. Immune profiles in hepatosplenic schistosomiasis mansoni after surgical treatments. J Int Med Res 1998; 26:43-9

20. Petroianu A, Petroianu LPG. A twelve-year follow-up of subtotal splenectomy and central splenorenal shunt for treatment of schistosomal portal hypertension. Folha Méd 1998; 116: 107-9.
21. Resende V, Petroianu A. Subtotal splenectomy for treatment of severe splenic injuries. J Trauma 1998; 44: 933-5.

22. Resende V, Petroianu A. Esplenectomia subtotal no tratamento do trauma esplênico grave. Rev Col Bras Cir 1997; 24: 205-8.

23. Lüdtke, F.E., Mack, S.C., Schuff-Werner, P. Splenic function after splenectomy for trauma. Acta Chir Scand 1989; 155:533-9.

24. Zoli G, Corazza GR, Dłaamato G, Bartoli R, Baldoni F, Gasparini G. Splenic autotransplantation after splenectomy: tuftisin activity correlates with residual splenic function. $\mathrm{Br} J$ Surg 1994; 81: 716-8.

25. Brandt CT, Araújo LB, Barbosa CM. Autotransplantation of spleen tissue in children with mansonic schistosomiasis who underwent splenectomy: Evaluation of splenic residual functions. Acta Cirúrgica Brasileira 1998; 13:212-216.

26. Carbonell-tatay F. Balsalobre B. Inmunidad humoral tras la esplenectomía en el adulto. Rev Clín Esp 1992; 190: 447-9.

27. Clayer MTR, Drew PA, Leong ASY, Jamieson GG. IgG-mediated phagocytosis in regenerated splenic tissue. Clin Exp Immunol 1994; 97:242-7.

28. Boasquevisque, EM, Moura, INS, Canine, MS, Filho MB, Lopes RLSF, Antonucci JB. Cintigrafia esplênica com eritrócitos marcados com ${ }^{99 m}$ tecnécio. Arq Bras Med 1986: 60: $117-22$.

Artigo recebido: 15//2/2000

Aceito para publicação: |9/06/200|

\section{À BEIRA DO LEITO}

Envie sua contribuição para esta nova seção da RAMB, que apresenta perguntas com respostas objetivas sobre condutas práticas. Sua colaboração é muito importante para nós.

Ramb - Rua São Carlos do Pinhal, 324 - CEP 01333-903 São Paulo - SP - Tel.: (11) 3266-6800 - ramb@amb.org.br 